SANTOS, E. P.; MEIRA, L. C.

Os desafios da educação das relações étnico-raciaise a formação de professores para a educação infantil

ARTIGOS

\title{
Os desafios da educação das relações étnico-raciais e a formação de professores para a educação infantil
}

\author{
Erisvaldo Pereira dos Santos \\ Universidade Federal de Ouro Preto (UFOP) \\ Mariana, Minas Gerais-BR \\ Ludmila Costa Meira \\ Universidade Federal de Ouro Preto (UFOP) \\ Mariana, Minas Gerais-BR
}

\begin{abstract}
RESUMO: Este trabalho é um dos resultados da pesquisa realizada com pedagogas que atuam na educação infantil no Município de Governador Valadares-MG. Seu objetivo principal foi investigar como pedagogas escolares que atuam especificamente na Educação Infantil orientam as práticas educativas com foco nas relações étnico-raciais, baseadaem uma educação antirracista. Amparamos esta pesquisa em marcos legais da educação brasileira e também em reflexões sobre as relações raciais no Brasil, com foco na crítica ao "mito da democracia racial", que continua desafiando a formação e a pratica docente. Na metodologia utilizamos de entrevistas semiestruturada e análise documental. Os resultados de nossa pesquisa aproximam-se de outras investigações sobre educação das relações étnico-raciais na Educação Infantil, remetendo para o campo de formação de professores, alguns desafios relacionados às bases teóricas e também às práticas pedagógicas desenvolvidas.
\end{abstract}

PALAVRAS-CHAVE: Educação infantil. Relações raciais. Formação docente.

\section{The challenges of education of ethnic-racial relations and teacher training for early childhood education}

\begin{abstract}
This work is one of the results of the research carried out with pedagogues that work in early childhood education in the Municipality of Governador Valadares-MG. Its main objective was to investigate how school educators who work specifically in Early Childhood Education orient educational practices with a focus on ethnic-racial relations based on an antiracist education. We support this research in legal frameworks of Brazilian education and also in reflections on racial relations in Brazil, focusing on the critique of the "myth of racial democracy", which continues to challenge teacher training and practice. In the methodology we use semi-structured interviews and documentary analysis. The results of our research are close to other investigations on the issue of education of ethnic-racial relations in Early Childhood Education referring to the field of teacher training, some challenges related to the theoretical bases and also to the pedagogical practices developed.
\end{abstract}

KEYWORDS: Infant education. Race relations. Teachertraining 


\section{Losdesafíos de la educación em relaciones étnico-raciales y la formación de professores para la educación de la primera infancia}

RESUMEN: Este trabajo es uno de los resultados de la investigación llevada a cabo con pedagogos que trabajan en la educación de la primera infancia en el Municipio de GovernadorValadares-MG. Su principal objetivo fue investigar cómo los educadores escolares que trabajan específicamente en la educación infantil orientan las prácticas educativas con un enfoque en las relaciones étnico-raciales, basadas en la educación antirracista. Apoyamos esta investigación en los marcos legales de la educación brasileña y también en reflexiones sobre las relaciones raciales en Brasil, centrándonos en la crítica del "mito de la democracia racial", que continúa desafiando la educación y la práctica docente. En la metodología utilizamos entrevistas semi-estructuradas y análisis documental. Los resultados de nuestra investigación están cerca de otras investigaciones sobre el tema de la educación de las relaciones étnico-raciales en la educación infantil temprana, que se refieren al campo de la formación docente, algunos desafíos relacionados con las bases teóricas y también con las prácticas pedagógicas desarrolladas.

PALABRAS-CLAVE: Educación infantil.Relaciones raciales.Formación docente 


\section{INTRODUÇÃO}

A constituição da Educação Infantil como primeira etapa da educação básicano Brasil foi marcada por fortes influências dos movimentos sociais, sobretudo da luta do movimento pró-creche. Uma das conquistas fundamentais dessas lutas encontra-se celebrada na Constituição Federal de 1988, que, em seu art.208, inciso $4^{\circ}$, considera a criança como sujeito de direito. Por sua vez, a pressão dos movimentos e as reflexões e ações de muitas educadoras reverberam na Lei de Diretrizes e Base da Educação Nacional - LDBEN, que, em seu Artigo 29, estabeleceu a educação Infantil como primeira etapa da educação básica. O reconhecimento dos direitos da criança, como umimportante marco legal tornou-se um dispositivo que foi utilizado para impulsionar a luta desses segmentos em busca da efetivação dessa conquista, traduzidas na oferta de amplo acesso e educação de qualidade, contemplando as especificidades das crianças atendidas nas instituições de Educação Infantil no Brasil.

Ao ser considerada como sujeito de direito e com especificidades a serem atendidas pelas instituições educativas, a criança brasileira passou a ser objeto de atenção do campo de formação de professores, que tomou como desafio produzir novas metodologias a partir de estudos fundamentados em reflexões sobre as dimensões afetiva e sociocultural da criança. No que se refere a esta ultima dimensão, o Estatuto da Criança e do Adolescente de 1990, (Lei 8.069/1990), no seu Art. 58 estabelece que "No processo educacional respeitar-se ao os valores culturais, artísticos e históricos próprios do contexto social da criança e do adolescente, garantindo-se a estes a liberdade de criação e o acesso às fontes de cultura." (BRASIL, 1990). A Lei de Diretrizes e Bases da Educação Nacional em seu Artigo 26-A estabelece a obrigatoriedade do ensino de história e cultura afro-brasileira e indígena nos estabelecimentos de ensino fundamental e médio, públicos e privados. Embora a educação infantil não faça parte de caput deste artigo, o que se depreende a partir do ECA e de outros dispositivos legais é que os valores culturais e artísticos da cultura afro-brasileira e indígena devem ser acessíveis à criança.

De acordo com as Diretrizes Curriculares para a Educação Infantil, o conhecimento ofertado às crianças deve proporcionar"o reconhecimento, a valorização, o respeito e a interação das crianças com as histórias e as culturas africanas, afro-brasileiras, bem como o combate ao racismo e à discriminação" (BRASIL, 2010, p. 12). No entanto, quem está diretamente envolvido com a temática das culturas africanas e afro-brasileira na educação sabeque ninguém ensina aquilo que não aprendeu. $O$ ensino das relações étnico-raciais não é tão simples como apenas ministrar um conteúdo. Essa prática exige que o docente tenha um conhecimento profundo de si, de suas convicções em relação a aspectos pessoais, profissionais e políticos. Sem que haja um compromisso sócio-político com a eliminação do racismo e todas a formas de discriminação, dificilmente o docente assumirá os desafios da educação das relações étnico-raciais. Há também a exigência do conhecimento amplo do campo científico. A soma desses aspectos contribui para a qualidade da participação do professor na formação da identidade do sujeito

No percurso de conquistas legais, destaca-se a implementação da Lei no. 10.639/2003, que trata da obrigatoriedade do ensino da História da Cultura Afro-Brasileira, bem como da História da África e dos Africanos, nos estabelecimentos de ensino públicos e privados brasileiros, do Ensino Fundamental até o Ensino Médio,e que impulsionou a discussão do tema nas instituições de ensino. É certo que só a legislação não garante a efetivação desse ensino, mas é evidente o aumento de políticas públicas educacionais com foco na questão racial a partir desta legislação, assim como de pesquisas acadêmicas e trabalhos realizados no âmbito das escolas, a partir de sua vigência. 
É importante ressaltar as Diretrizes Curriculares Nacionais para o Curso de Graduação em Pedagogia e Licenciatura (2006), legislação que regulamenta a formação docente como outro marco relevante, pois, ao descrever a ação docente em seu Artigo 2, inciso 1, atribui ao mesmo sua parcela de contribuição para que o ensino das relações étnico-raciais no âmbito das instituições seja efetivo:

$\S 1^{\circ}$ Compreende-se a docência como ação educativa e processo pedagógico metódico e intencional, construído em relações sociais, étnico-raciais e produtivas, as quais influenciam conceitos, princípios e objetivos da Pedagogia, desenvolvendo-se na articulação entre conhecimentos científicos e culturais, valores éticos e estéticos inerentes a processos de aprendizagem, de socialização e de construção do conhecimento, no âmbito do diálogo entre diferentes visões de mundo (BRASIL, 2006, p. 11).

Ao considerar as relações étnico-raciais como fazendo parte da intencionalidade da ação educativa e do processo pedagógico, as DCNs da Pedagogia e das Licenciaturas oferecem as bases para o diálogo entre os campos da educação infantil e as relações étnico-raciais, ancorado nos marcos teórico e legal. Dessa maneira, evidencia a importância da formação dos profissionais que sejam capazes de desenvolver uma prática voltada para o ensino das relações étnico-raciais, contribuindo para acabar com os estereótipos racistas, que são negados pelo funcionamento do "mito da democracia racial no Brasil".

A incursão narrativa e ideológica do "mito da democracia racial" provocou uma ambiguidade no processo de construção da identidade racial no Brasil,que sustenta, até os dias atuais, a falsa sensação de harmonia entre as raças.Cavalleiro (1998), que denomina essa ideologia como "democracia racial de fachada", considera que os efeitos de sua perversidade são percebidos principalmente nas escolas. Ao distanciar desse espaço a importância de proporcionar uma convivência multiétnica de reconhecimento e de valorização, as escolas atuam, dessa forma, como mantenedoras das diferenças na perspectiva do preconceito.

O desmascaramento do "mito da democracia racial" tem sido uma tarefa assumida por teóricos das relações raciais no Brasil, como o sociólogo Florestan Fernandes (1978, p. 249-269) e, sobretudo, pelos movimentos sociais negros, em sua luta contra o racismo e em prol de uma sociedade pluriétnica. Nessa luta, a discussão da questão étnico-racial foi assumida, a partir de uma articulação política com outros atores que se sensibilizaram pela causa e deram maior visibilidade ao debate que levou o reconhecimento da contribuição do povo negro na formação da nação e expôs a incidência negativa da forma como a questão racial vinha sendo tratada, na vida e no dia a dia dessa população. Nesse sentido, os movimentos sociais negros foram os principais protagonistasda luta pela igualdade e pela garantia de direitos do povo negro, contribuindo para ressignificar o conceito de raça no Brasil como uma construção social.

Ao politizar a raça, esse movimento social desvela a sua construção no contexto das relações de poder, rompendo com visões distorcidas, negativas e naturalizadas sobre os negros, sua história, cultura, práticas e conhecimentos; retira a população negra do lugar da suposta inferioridade racial pregada pelo racismo e interpreta afirmativamente a raça como construção social; coloca em xeque o mito da democracia racial. (GOMES, 2012, p. 731)

O fato que é que as teorias raciaisdesenvolvidas na segunda metade do século XIX chancelavam a hierarquização das raças, afirmando a condição de superioridade da raça branca como um fenômeno natural e que, portanto, deveria ser aceito por índios, pretos e mestiços. Estes, por sua vez, deveriam se embranquecer para serem consideradoshomens civilizados. Ao lado do branqueamento, o que se sucede a este racismo científico é justamente uma ideologia que propugnava a existência de uma harmonia racial entre brancos, índios e negros no Brasil. 
A partir da década de 1980, o campo da pesquisa em educação no Brasil começou a desmascarar o "mito da democracia racial", desvelando os efeitos do racismo na sala de aula e indicando o "Silêncio" como "um ritual pedagógico a favor da discriminação racial" (GONÇALVES, 1985). É na esteira dessas analises críticas sobre o racismo e a discriminação racial, amparada nos marcos legais da educação brasileira, que se inscreve este trabalho como resultado de uma pesquisa no mestrado em Educação, cujo objetivo geral foi investigar como pedagogas escolares que atuam especificamente na Educação Infantil do município de Governador Valadares-MG orientam as práticas educativas com foco nas relações étnico-raciais, com base em uma educação antirracista. Dessa forma, foram evidenciados dois campos emergentes no âmbito das pesquisas acadêmicas em Educação, a Educação Infantil e as relações étnico-raciais.

Uma das justificativas da relevância da pesquisa é pensada a partir da compreensão de que as relações étnico-raciais se configuram no âmbito escolar ainda na Educação Infantil. Porém, as relações étnico-raciais são invisibilizadas em práticas do dia a dia, sem que haja uma indagação a respeito delas e do que revelam. A partir dessa compreensão, espera-se que este estudo sirva de subsídio teórico para a elaboração de políticas públicas educacionais com foco na temática racial a partir da Educação infantil, e que também amplie o conhecimento das pedagogas que atuam nesse segmento.Nossa perspectiva é em prol de uma educação que considere a importância de trabalhar a questão étnico-racial desde atenra infância, a fim de contribuir para o desenvolvimento da identidade desses sujeitos em um cenário de reconhecimento, de valorização e de respeito à alteridade.

O procedimento metodológico utilizado para o desenvolvimento desta pesquisa de caráter qualitativo foi o estudo de caso, pois possibilitou melhor aproximação da realidade do objeto em estudo. Os instrumentos para produção de dados para análise foram entrevistas semiestruturadas e análise documental dos Projetos Políticos Pedagógicos (PPPs) das instituições onde atuavam as pedagogas participantes da pesquisa. Essas profissionais foram selecionadas a partir de dois critérios: atuação em instituição que atende especificamente à Educação Infantil e efetivação no cargo de pedagoga escolar pelo concurso público municipal de 2010, quando houve uma seleção específica para a categoria. Foram elencadas três categorias para a análise dos dadose construídas a partir dos objetivos: 1)Experiências com as relações étnico-raciais; 2) Conhecimento teórico das pedagogas; 3) Valorização da temática étnico-racial.

\section{CONSIDERAÇÕES FINAIS}

As discussões apresentadas, até aqui, apontam para uma reflexão sobre a importância de considerar o ensino das relações étnico-raciais na prática da Educação Infantil. Para que essa proposta se efetive é necessário um conhecimento específico de ambos os campos. Com efeito, sem que estas reflexões estejam devidamente presentes na formação inicial dos professores da educação infantil, é muito difícil esperar que as relações étnico-raciais faça parte do currículo da educação infantil. Não basta a existência de uma legislação que estabeleça e ampare esta implementação, se não existirem bases teóricas e práticas pedagógicas coerentes com a valorização da alteridade, os atores não vão se comprometer com uma educação antirracista na educação dos pequenos. Nesse sentido, como primeira etapa da educação básica, a Educação Infantil só poderá garantir qualidade da educação com profissionais formados para atender as especificidades das crianças na primeira infância.

As Diretrizes Curriculares Nacionais para a Educação Infantil - (2010) vêm chancelar a importância do ensino das relações étnico-raciais desde a Educação Infantil e orientam as propostas pedagógicas, afim de que as instituições propiciem às crianças o direito de se desenvolverem com qualidade e fora da perspectiva da 
naturalização imposta pelas teorias raciais. Essedocumento funciona como uma ferramenta de implementação da Lei no. 10.639/2003, que, muitas vezes, não é objeto de interesse dos profissionais que atuam nesse segmento.

Considerando que a criança, ao vivenciar suas experiências sociais, se apropria e reestrutura seu pensamento, para constituir, dessa forma, suas estruturas cognitivas, sociais, afetivas e físicas, o contato com as culturas africanas e afro-brasileiras contribui para o desenvolvimento de sua identidade, bem como para a valorização e o respeito à diversidade.

Ao mencionar subliminarmente as teorias raciais, neste estudo, estamos entendendo que a formação de professores para a educação das relações étnico-raciais tem como um dos seus desafios o processo de apropriação de uma perspectiva crítica do "mito da democracia racial", pois se trata de um forte dispositivo ideológico que, conforme observado no trabalho das pedagogas escolares, está presente na atualidade dentro das instituições escolares e em outras esferas sociais. Dessa forma, a escola como ambiente que abarca todas as diversidades torna-se um local propicio para a efetivação de práticas racistas e de preconceito, se não atuar contrapondo as questões raciais silenciadas pelo mito supracitado. Nossa pesquisa evidenciou a necessidade de qualificação profissional para a construção de políticas públicas e desenvolvimento de práticas com foco no ensino das relações étnico-raciais.

A partir da lei 10.639/2003 o número de pesquisas que abarcam a educação infantil e as relações étnico-raciais tem aumentado e consequentemente revelando os principais desafios que interferem na continuidade ou descontinuidade do ensino das relações étnico-raciais na educação infantil. Dessa forma, apresentamos essa legislação como, contribuição impar impulsionando práticas antirracistas visando promover um ambiente onde todas as crianças tenham a oportunidade de se constituir observando variadas possibilidades.

Nesse estudo identificamos que não houve um processo de implementação da Lei no. 10.639/2003 no município de Governador Valadares-MG. A análise dos PPPs das instituições evidenciou que esses documentos não contemplavam a temática. As entrevistas, por sua vez, revelaram que as ações com foco nas relações étnico-raciais aconteciam de forma pontual, tanto em relação à oferta pela Secretaria Municipal de Educação, quanto no âmbito das instituições de Educação Infantil.

A visão do negro apresentada pelas pedagogas revelam que há uma percepção de alteração da condição do negro na sociedade, sua contribuição e valorização, mas que, no entanto ainda não se configurou em mudanças substantivas na prática pedagógica desenvolvida. Associado a esse aspecto se ancora a perspectiva de que a temática racial não reverbera, mesmo diante de situações de racismo e preconceito entre crianças pequenas. Nossa pesquisa evidenciou que a temática é tratada somente de forma pontual, assim como as formações ofertadas pela secretaria municipal de educação. Isso aponta para investigações que possamconhecer e evidenciar qual tem sido o papel dos movimentos sociais e negro diante da implementação da temática das relações étnico-raciais na Educação Infantil. Nossa hipótese é de que será cada vez mais difícil defender uma educação democrática e socialmente referenciada, sem atuação e pressão dos movimentos sociais, sobretudo dos movimentos negros, neste caso mais específico. 
DOI https://doi.org/10.31639/rbpfp.v\%vi\%i.256

\section{REFERÊNCIAS}

ALCARAZ, Rita de Cassia Moser. Políticas de leitura para a infância no município de Curitiba: o livro como direito à promoção da igualdade racial. 2018. 226f. Tese (Doutorado em Educação) - Universidade Federal do Paraná, Curitiba, 2018.

BRASIL. Constituição. Constituição da República Federativa do Brasil. Brasília, DF: Presidência da República, 1988[2016]. Disponível em: <http://www.planalto.gov.br/ccivil_03/constituicao/constituicao.htm>. Acesso em: 02 abr. 2019.

BRASIL. Lei nº. 9.394, de 20 de dezembro de 1996. Estabelece asDiretrizes e Bases da Educação Nacional. Brasília, DF: Senado, 20 de dezembro1996. Disponível em: <http://www.planalto.gov.br/ccivil_03/leis//9394. htm>. Acesso em: 03 abr. 2019.

BRASIL. Lei no. 8.069, de 13 de julho de 1990. Dispõe sobre o Estatuto da Criança e do Adolescente e dá outras providências. Diário Oficial da União, Brasília, DF, 16 de julho 1990.

BRASIL.Lei no. 10.639, de 9 de janeiro de 2003, que altera a Lei n. 9.394, de 20 de dezembrode 1996, e estabelece asDiretrizes e bases da educação nacional, para incluir no currículo oficial da Rede de Ensino a obrigatoriedade da temática "História e cultura afro-brasileira", e dá outras providências. Diário Oficial da União, Brasília, DF, 10 de janeiro de 2003.

BRASIL. Conselho Nacional de Educação. Conselho Pleno. Resolução $n^{\circ}$. 1, de 15 de maio de 2006, que institui Diretrizes Curriculares Nacionais para os Cursos de Graduação em Pedagogia, licenciatura. Diário Oficial da União, Brasília, DF, 16 de maio de 2006. Disponível em: <http://portal.mec.gov.br/cne/arquivos/ pdf/rcp01_06.pdf>. Acesso em: 03 jun. 2019.

BRASIL. Ministério da Educação. Secretaria de Educação Básica. Diretrizes Curriculares Nacionais para a Educação Infantil. Brasília, DF: MEC/SEB, 2010. Disponível em: <http://portal.mec.gov.br/dmdocuments/ parecer_ceb_22.98.pdf>. Acesso em: 22 jan. 2019.

BRASIL. Ministério da Educação. Secretaria de Educação Básica. Diretrizes Curriculares Nacionais para a Educação das Relações Étnico-Raciais e para o Ensino de História e Cultura Afro-Brasileira. Brasília, DF: MEC/SECAD, 2005

CASTRO, Moacir Silva de. Educação para as relações étnico-raciais: concepções e práticas de professoras da educação infantil. 2015. 139f. Dissertação (Mestrado em Gestão e Práticas Educacionais) - Universidade Nove de Julho, São Paulo, 2015.

CAVALLEIRO, Eliane S. Do silêncio do lar ao silêncio escolar: racismo, preconceito e discriminação na educação infantil. 1998. 225f. Dissertação (Mestrado em Educação) - Universidade de São Paulo, São Paulo, 1998.

FERNANDES, Florestan, A integração do negro na sociedade de classes. $3^{\text {a }}$ ed. Vol. 1. São Paulo: Editora Ática, 1978.

GOMES, Nilma Lino. Movimento negro e educação: ressignificando e politizando a raça. Educ. Soc. [online], v.33, n.120, p.727-744, 2012. Disponível em: <http://www.scielo.br/pdf/es/v33n120/05.pdf> Acesso em 13/09/2019. 
GOMES, NilmaLino.(Org.). Práticas pedagógicas de trabalho com relações étnico-raciais na escola na perspectiva da Lei $n^{\circ}$ 10.639/03. Brasilia, DF: MEC, Unesco, 2012b.

GONÇALVES, Luiz Alberto de Oliveira. O silêncio: um ritual pedagógico a favor da discriminação racial. $342 f$. 1985. Dissertação (Mestrado em Educação) - Universidade Federal de Minas Gerais, Belo Horizonte, 1985.

OLIVEIRA, Fabiana. Um estudo sobre a creche: o que as práticas educativas produzem e revelam sobre a questão racial? 2004. 119f. Dissertação (Mestrado em Educação) - Universidade Federal de São Carlos, São Carlos, 2004.

OLIVEIRA, Verediane Cintia de Souza. Educação das relações étnico-raciais e estratégias ideológicas no acervo do PNBE 2008 para educação infantil. 2010. 190f. Dissertação (Mestrado em Educação) - Universidade Federal do Paraná, Paraná, 2010.

OLIVEIRA, Waldete Tristão Farias. Diversidade étnico-racial no currículo da educação infantil: o estudo das práticas educativas de uma EMEI da cidade de São Paulo. 2017. 281f. Tese (Doutorado em Educação) Universidade de São Paulo, São Paulo 2017.

PEREIRA, Erika Jennifer Honório. "Tia, existe flor preta?": educar para as relações étnico-raciais. 2015. 183f. Dissertação (Mestrado em Educação) - Universidade do Estado do Rio de Janeiro, Rio de Janeiro, 2015.

SARAIVA, Camila Fernanda. Educação infantil na perspectiva das relações étnico-raciais: relato de duas experiências de formação continuada de professores no município de Santo André. 2009. 353f. Dissertação (Mestrado em Educação) - Pontifícia Universidade Católica de São Paulo, São Paulo, 2009.

SANTOS, E. P.; MEIRA, L. C.

Os desafios da educação das relações étnico-raciaise a formação de professores para a educação infantil Formação Docente - Revista Brasileira de Pesquisa sobre Formação de Professores

Vol. 11, no. 22 (p. 13-20) 31 dez. 2019 